\title{
Considerações filogenéticas e biogeografia histórica dos malacostráceos (decápodes e isópodes) cenozóicos do Brasil
}

\author{
Vladimir de Araújo Távora ${ }^{1,2}$, Gleicy Mara Carvalho Paixão ${ }^{1,3}$ \& Fabrício Araújo da Silva ${ }^{1,2}$
}

\begin{abstract}
Resumo Análises da Biogeografia Histórica da paleocarcinofauna cenozóica brasileira, encerrada nas formações Maria Farinha (Paleoceno), Tremembé (Oligoceno) e Pirabas (Mioceno), revelaram que as mesmas guardam afinidades com as cretáceas do mar de Tethys e possuem aspecto moderno. Sua distribuição paleobiogeográfica permite enquadrar o seu surgimento, dispersão e irradiação nos padrões fauna de origem tetiana, fauna de origem de alta latitude sul e fauna anfitropical, sendo que a maior parte tem afinidade com a fauna de origem tetiana, que teve basicamente dois caminhos de dispersão, migração no sentido oeste a partir do sul da Europa e Mar de Tethys, para leste atingindo a costa leste dos Estados Unidos e região caribeana, e em seguida, chegando na costa oeste dos Estados Unidos e América do Sul, pelo corredor americano central; e para leste da Europa e Mar de Tethys e Japão, a partir da costa leste dos Estados Unidos, em um caminho inverso ao primeiro. As relações filogenéticas definidas até o momento sugerem que a superfamília Thalassinoidea originou-se provavelmente de um grupo primitivo da infraordem Caridea, e que a família Retroplumidae (gênero Costacopluma) presente na Formação Maria Farinha, é ancestral direta dos ocipodídeos cenozóicos (representados na Formação Pirabas pelo gênero $U c a$ ), ocupando os mesmos nichos ecológicos e com tolerâncias ambientais similares. Também as similaridades morfológicas sugerem monofiletismo entre Xanthoidea e Portunoidea, que a partir do Paleoceno, os goneplacídeos, também monofilético, originou outro grupo-irmão, a família Hexapodidae, e o gênero Glyphithyreus possui caracteres afins da subfamília Eucratopsinae, membro do grande grupo Xanthoidea.
\end{abstract}

Palavras-chave: Biogeografia histórica, paleocarcinofauna, cenozóico.

\begin{abstract}
Historical biogeography and phylogenetic approaches of the cenozoic malacostracean (decapods and isopods) of Brazil. This work deals the analysis of the Historical Biogeography of the brazilian cenozoic paleocarcinofauna, recorded in the Maria Farinha, Tremembé and Pirabas formations. This taxa has affinity with the tethian carcinofaunas and modern aspect. The paleobiogeographic setting allows to situate their biological events of the origin, dispersional and irradiation trends in the tethian, south high latitude and amphitropical origins. The majority of the brazilian carcinofauna has affinity with the tethian faune, that migrate in two seaways, west and east. The phylogenetic relationships suggest appearence of the Thalassinoidea group from the Caridea infraordo. The Retroplumidae family (genus Costacopluma) recorded at Maria Farinha Formation is directed related with the cenozoic ocypodid (i.e. genus $U c a$ at Pirabas Formation, living in the same ecological niches and environmental tolerances. Also, the morphological similarities between Xanthoidea and Portunoidea in the Paleocene, suggest monophyletic relationships with Goneplacidae and Hexapodidae. The detailed phylogenetic studies in Goneplacidae family reveals that Glyphithyreus genus is related with Eucratopsinae subfamily.
\end{abstract}

Keywords: Historical Biogeography, palaeocarcinofaune, cenozoic.

INTRODUÇÃO Os crustáceos decápodes fósseis no Brasil são registrados em três unidades litoestratigráficas, compreendendo formas intimamente relacionadas com as atuais. Assim, até o momento foram reconhecidos restos de braquiúres nas formações Maria Farinha (Paleoceno do Estado de Pernambuco- nove espécies, sendo uma indeterminada), Tremembé (Oligoceno do Estado de São Paulo- duas espécies) e Pirabas (Mioceno do Estado do Pará- 12 espécies sendo uma indeterminada). A localização geográfica de ocorrência destas unidades geológicas é mostrada na figura 1.

No Brasil estudos sobre a paleocarcinofauna cenozóica tiveram uma abordagem sistemática e mais recentemente, tafonômica (Feldmann \& Martins Neto 1995; Martins-Neto 2001; Távora 2001; Távora \& Souza 2000; Távora \& Silva Junior 2002; Távora \& Viana 2003; Távora \& Miranda 2004; Távora et al. 2002, 2005a, 2005b, 2006). Entretanto, é necessário que este campo de conhecimento seja ampliado, principalmente no sentido biogeográfico, para que possa recompor as

1 - Universidade Federal do Pará, Instituto de Geociências, Faculdade de Geologia, Laboratório de Paleontologia, Belém (PA), Brasil.

E-mail: vladimir@ufpa.br

2 - Universidade Federal do Pará, Instituto de Geociências, Faculdade de Geologia, Programa de Educação Tutorial MEC/SESu/DIFES/ PET, Belém (PA), Brasil.

3 - Universidade Federal do Pará, Instituto de Geociências, Faculdade deGeologia, Programa de Iniciação Científica PIBIC/CNPq, Belém (PA), Brasil. 


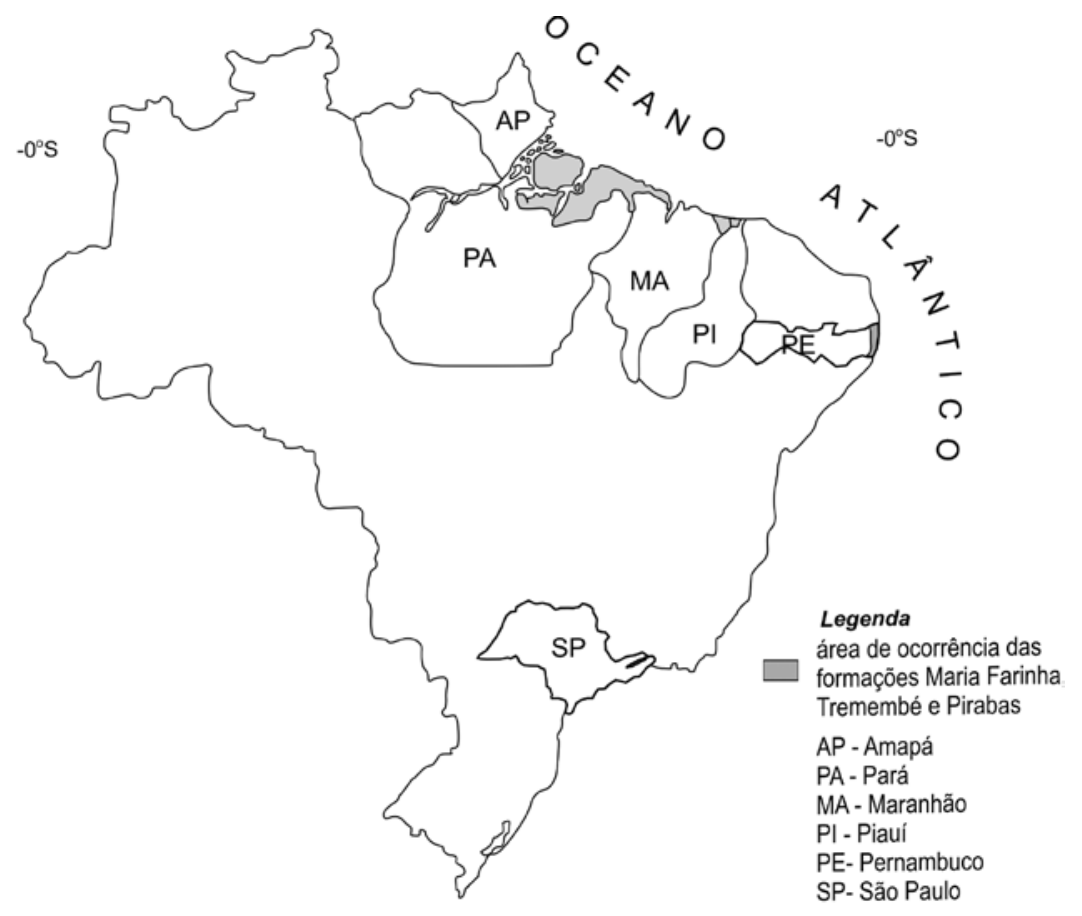

Figura 1 - Mapa de localização das áreas de ocorrência das formações Maria Farinha, Tremembé e Pirabas.

rotas de migração dos táxons encontrados como fósseis, interligando-os com as ocorrências européias e principalmente do continente americano, que guarda uma carcinofauna bastante similar e intimamente relacionada filogeneticamente. Para tanto, essa pesquisa objetiva traçar pelo menos em linhas gerais, as linhagens evolutivas das formas brasileiras.

Feldmann $(2003,2006)$ realiza uma abordagem crítica sobre os crustáceos decápodes do mundo, ressaltando a sua importância com elementos úteis para reconstruções geológicas. $\mathrm{O}$ autor ao comparar o volume de dados entre as paleocarcinofaunas dos hemisférios norte e sul americano, sugeriu que o modesto conhecimento das formas do hemisfério sul deve-se principalmente a falta de pesquisadores, e a localização geográfica dos prováveis sítios deposicionais, situados na margem continental, cuja intensa atividade tectônica durante a tafrogenia pode ter apagado o registro existente, bem como não ter favorecido a sua expansão nos nichos ecológicos criados quando da invasão do mar nas áreas ao longo da margem continental brasileira, devido a instabilidade ambiental no momento de sua instalação.

Assim, este trabalho trata sobre a Biogeografia da paleocarcinofauna cenozóica brasileira, sob a abordagem Histórica, que lida particularmente com a reconstrução da história de áreas de endemismo com base na congruência de informação filogenética gerada por diferentes táxons não relacionados, mas que ocorrem nessas áreas (Morrone \& Crisci 1995). Neste campo, estudamse os fatores que governam a história da distribuição geográfica dos organismos e as explanações históricas para a distribuição geográfica dos organismos, considerando os processos evolutivos e geológicos (Cecca 2002). Considerando a relação intrínseca entre Biogeografia e Filogenia, também apresenta-se nesta pesquisa as principais relações filogenéticas entre os táxons reconhecidos.

OS MALACOSTRÁCEOS Os malacostráceos são compostos dominantemente pelas superordens Peracarida e Eucarida, as duas principais linhas evolutivas dentro desta subclasse, bem sucedidas devido a pluralidade morfoanatômica e ambiental. A ordem dominante dos Eucarida é a Decapoda, encontrada em todos os habitats, e incluem os camarões, lagostas e caranguejos, comportando aproximadamente 10.000 espécies, dominantemente marinhas e bentônicas vágeis (Storer 2003; Ruppert et al. 2005).

O caráter principal da evolução dos decápodes é a transformação de um ancestral alongado, nectônico e com corpo similar ao de um camarão, em um animal mais curto, achatado, reptante e com a forma de um caranguejo. A classificação dos decápodes é baseada na extensão desta transformação, que de maneira simplificada resultou em três formas básicas: semelhante a um camarão (Penaeidea, Stenopodidea, Caridea), semelhante a uma lagosta (Astacidea, Thalassinidea, Palinura), e semelhante a um caranguejo (Anomura, Brachyura) (Ruppert et al. op. cit.).

Segundo Garassimo et al. (2002), os carídeos mais antigos foram os gêneros Acanthinopus e Leithorax, reconhecidos em estratos triássicos da Itália. A partir do Jurássico, a dominância genérica parece ter aumentado, considerando que foram descritos quatro gêneros, 
outros sete para o Cretáceo, e cinco para o Terciário. No Brasil, a infraordem está até o momento representada por um gênero no Cretáceo (Beurlenia), três no Oligoceno da Bacia de Taubaté (Bechleja, Propalaemon e Pseudocaridinella), estando este último gênero também registrado na Formação Cícero Dantas. Em particular, a família Paleomonidae- camarões de água doce, é a mais diversa, sendo composta pelos gêneros Alburnia, Bechleja, Palaemon e Propalaemon, cujas amplitudes temporais correspondem ao intervalo Cretáceo ao Recente, bem como por Delclosia e Yongjiacaris, registrados apenas no Cretáceo da Espanha e China, respectivamente.

Os isópodes perfazem uma ordem de peracarídeos com grande representatividade numérica e diversidade específica. São cerca de 4.000 espécies descritas, com ampla distribuição geográfica e importância ecológica no substrato dos diversos ambientes aquáticos. A maioria vive no mar, mas existem representantes na água doce e terra firme, que experimentam estratégias alimentares variadas, entre herbívoros, carnívoros, omnívoros, parasitas e saprófagos (Ruppert et al. op. cit.).

Os isópodes fósseis constituem um dos grupos cuja classificação e interpretação são consideradas complexas, principalmente devido a sua grande variabilidade morfológica na diferenciação das regiões da carapaça, e no estilo bifásico das ecdises. Considerando a ordem como um todo, a forma mais comum de preservação corresponde à porção posterior, onde o exoesqueleto se diferencia primeiro, peculiaridade que dificulta a identificação taxonômica, pois as feições diagnósticas estão no céfalo, região normalmente mal preservada no registro fóssil. Para o gênero Palaega estão definidas cerca de 27 espécies, que provavelmente não corresponde ao número real, já que apenas $30 \%$ delas possuem céfalos preservados (Wieder \& Feldmann 1992; Feldmann \& Goolaerts 2005).

A grande irradiação adaptativa e alto grau de endemismo da família Cirolanidae permitem indubitavelmente a compreensão da evolução da ordem Isopoda como um todo, muito embora os estudos até o momento sejam pontuais (Almeida 2003).

\section{GEOLOGIA}

Formação Maria Farinha A Formação Maria Farinha possui uma grande variabilidade litológica, caracterizando-se por uma seqüência de calcários fossilíferos detríticos com estratificação plano paralela. O perfil consiste basicamente em duas seções. A inferior, de pequena espessura, constituída por um calcário litográfico, com fósseis relativamente raros, esparsamente distribuídos, sem acumulações locais. A segunda seção, mais espessa, começa com calcários detríticos finos e puros, passando para calcários dolomitizados e calcários detríticos argilosos com intercalações de camadas de argila calcífera de reduzida espessura $(0,10 \mathrm{~m}$ a $0,25 \mathrm{~m})$. Esta seqüência se identifica como uma fase regressiva após a transgressão gramame (Buerlen 1959; Muniz inédito). Aqui, os fósseis mostram as mesmas alterações rápidas que o caráter litológico. Há leitos estéreis e outros ricos em fósseis; há acumulações locais de conchas e leitos com abundância de fósseis em homogênea distribuição, sendo abundantes os moluscos e crustáceos.

White (1887) e Maury $(1925,1930)$ descreveram o maior número de fósseis dessa unidade que foi depositada no Paleoceno em ambiente costeiro raso com variadas condições ecológicas, refletindo provavelmente movimentos oscilatórios da linha de costa (Beurlen 1967). Os demais elementos fossilíferos desta formação estão representados por corais, briozoários, escafópodes, nautilóides, esclerodermitos de holoturóides, placas de equinóídes, icnofósseis, foraminíferos e vegetais. Os táxons mais característicos da Formação Maria Farinha são os nautilóides Cimonia pernambucensis e Hercoglossa lamegoi, bem como o gastrópode Campanile buarquianus, e o crustáceo Calianassa.

Formação Tremembé AFormação Tremembé, inicialmente definida por Almeida (1958), corresponde na concepção atual a um sistema lacustre do tipo Playa-Lake, oligomítico e eutrófico, depositado em clima semi-árido, de idade oligocênica, desenvolvido na porção central da Bacia de Taubaté, Estado de São Paulo. A partir de dados de sondagens e afloramentos, as principais litofácies reconhecidas na Formação Tremembé compreendem argilitos verdes maciços, ritmitos de folhelhos e margas, dolomitos e arenitos, sendo esta última a única litofácies afossilífera até o momento (Riccomini, 1989; Riccomini et al. 1996; Suguio 1969; Torres-Ribeiro 2004). Os argilitos verdes depositaram-se em épocas de lâmina d'água baixa no lago e os folhelhos correspondem à sedimentação lacustre com lâmina de água espessa.

Formação Pirabas A Formação Pirabas (Maury 1925) ocorre descontinuamente nos estados do Pará, Maranhão e Piauí, sendo que no Pará ocorre em superfície e subsuperfície na região nordeste do Estado, nas zonas fisiográficas do Salgado e Bragantina. Litologicamente é constituída por calcários cinza de composição variável (coquinas, biohermitos, micritos, dolomicritos, margas e bioclasitos) intercalados com calcarenitos e folhelhos negros, depositados durante o Mioceno Inferior em ambiente marinho de águas límpidas, rasas, nerítico, próximo ao litoral de mar aberto, onde o clima deveria ter sido quente e a costa baixa (Ferreira \& Cunha 1957; Ferreira 1982). Este ambiente acha-se geneticamente relacionado com outros depósitos comuns a sistemas estuarinos, tais como delta de maré, baía/laguna estuarina, planície de maré e mangue, englobados na seqüência Pirabas/Barreiras, cujo sistema deposicional deveria incluir um complexo de vales incisos separados por áreas de interflúvios, aproximando-se bastante da configuração da atual margem equatorial localizada entre os estados do Amapá e Maranhão (Góes et al 1990; Rossetti 2000; Rossetti \& Góes 2004).

Subseqüente a este evento deposicional, dominantemente transgressivo e oscilatório, predominou a sedimentação de uma outra seqüência, regressiva e siliciclástica (Grupo Barreiras), cujas estruturas sedimentares e conteúdo palinológico típico do Mesomioceno indicam certa contemporaneidade e gradação entre as 
seqüências Pirabas e Barreiras (Góes et al. 1990).

CARCINOELEMENTOS FÓSSEIS DO CENOZÓICO BRASILEIRO Na lista abaixo são apresentados todos os táxons de crustáceos malacostráceos registrados como fósseis no Brasil, até o momento. $\mathrm{O}$ arranjo taxonômico segue a proposta de Martin \& Davis (2001) até o nível de superfamília. Para os níveis inferiores adotase Glaessner (1969) e variada bibliografia complementar específica, tais como Schweitzer \& Feldmann (2000c), Tudge (1997) e Wieder \& Feldmann (1992).

\section{Formação Maria Farinha}

Superordem Eucarida Calman, 1904

Ordem Decapoda Latreille, 1803/Infraordem Thalassinidea Latreille, 1831

Superfamília Calianassoidea Dana,1852/Família Callianassidae Dana, 1852

Protocalianassa archiaci (Milne-Edwards, 1860)/Calianassa fragilis Biffar,1971

Família Ctenochelidae Manning \& Felder,1991/Ctenocheles holthuisi Rodrigues, 1978

Família Upogebidae Say,1818/Upogebia affinis Say,1818 Infraordem Anomura MacLeay, 1838

Superfamília Paguroidea Latreille, 1802/Família Diogenidae Ortmann, 1892

Dardanus fucosus Biffar \& Provenzano,1972/D. insignis (Saussure, 1858)

Infraordem Brachyura Latreille, 1802/Seção Oxystomata H.Milne-Edwards, 1834

Superfamília Calappoidea Haan, 1833

Família Necrocarcinidae Förster, 1968/Necrocarcinus sp.

Seção Brachyrhyncha Borradaile, 1907

Superfamília Xanthoidea MacLeay, 1838

Família Goneplacidae Macleay, 1838/ Glyphithyreus sturgeoni Feldmann et al., 1998

Superfamília Ocypodoidea Rafinesque, 1815

Família Retroplumidae Gill, 1894/Costacopluma nordestina Feldmann \& Martins-Neto,1995

\section{Formação Tremembé}

Superordem Peracarida Calman, 1904

Ordem Isopoda Latreille, 1817/Subordem Flabellifera Sars, 1882

Família Cirolanidae Dana, 1852/Palaega tremembeensis Martins-Neto, 2001

Superordem Eucarida Calman, 1904/Ordem Decapoda Latreille, 1803

Subordem Pleocyemata Burkenroad, 1963/Infraordem Caridea Dana, 1852

Superfamília Paleomonoidea Rafinesque, 1815

Família Palaemonidae Rafinesque, 1815/Bechleja robusta Martins-Neto,1991/Propalaemon longispinata Martins-Neto, 1991

\section{Formação Pirabas}

Superordem Eucarida Calman, 1904

Ordem Decapoda Latreille, 1803/Subordem Pleocyemata Burkenroad, 1963

Infraordem Brachyura Latreille, 1803/Seção Oxysto- mata H.Milne-Edwards, 1834

Superfamília Calappoidea Haan, 1833

Família Calappidae Haan, 1833/Calappa circularis Beurlen, 1958/Acanthocarpus obscurus (Rathbun)/Calappilia broksi Ross \& Scolaro, 1964

Família Hepatidae Stimpson, 1871/Hepatella amazonica Beurlen, 1958

Familia Leucosidae Samouelle,1819/Randallia sp./ Typilobus unispinatus Martins-Neto, 2001

Seção Oxyrhyncha Latreille, 1803/Superfamília Parthenopoidea MacLeay, 1838

Familia Parthenopidae Macleay, 1838/Parthenope tuberculata Beurlen, 1958

Seção Cancridae Latreille,1803/Superfamília Cancroidea Latreille, 1802

Familia Cancridae Latreille,1802/Tasadia tuberculatus (Beurlen,1958)

Seção Brachirhyncha Borradaile, 1907/Superfamilia Portunoidea Ranifesque, 1815

Familia Portunidea Ranifesque, 1815/Arenaeus cribarius (Lamarck, 1818)/Portunus atecuicitilis Vega et al.,1999/P. haitensis Rathbun, 1924/P. pirabensis Martins-Neto,2001/P. spinimanus Latreille, 1819/P. sp./ Callinectes paraensis Beurlen, 1958/C. pirabensis Brito, 1971/C. reticulatus Rathbun, 1918/Necronectes tajinensis Vega et al.,1999/Scylla costata Rathbun, 1930/ Euphylax septendentatus Beurlen, 1958

Superfamilia Xanthoidea Dana,1851/Familia Xanthidae Dana,1851/Panopeus capanemensis Martins-Neto,2001/Tetraxanthus rathbunae Chace,1931/Paratumidocarcinus marajoarus Martins-Neto,2001

Família Grapsidae Macleay,1838/Sesarma paraensis Beurlen, 1958

Superfamília Ocypodoidea Rafinesque,1815/Família Ocypodidae Rafinesque,1815/Uca maracoani Latreille, 1802

\section{RESULTADOS}

Filogenia A classificação sistemática clássica dos malacostráceos decápodes e isópodes está baseada nos caracteres morfológicos das formas adultas, resultando em arranjos filogenéticos empíricos. Para avançar nestes estudos foram incluídos como elementos de classificação, as seqüências moleculares, neuroanatômicos das partes moles e genéticos que, combinados, podem definir as relações filogenéticas entre os táxons, sendo que os resultados não são compatíveis com o registro fóssil, onde as partes moles estão ausentes. A complexa história deste grupo está definida até o momento para os táxons viventes hoje, onde as análises cladísticas já revelaram possíveis relações parafiléticas e polifiléticas entre anomúreos previamente considerados monofiléticos (Feldmann 2003; Tudge 1997).

Segundo Vega et al. (2001b) e Feldmann (2003), a reconstrução da história filogenética dos decápodes deve utilizar alternativas eficazes, informações que podem ser obtidas através do estudo das formas atuais, e caracteres que podem ser extrapolados para os fósseis. Assim sendo, dos animais recentes se analisam toda a morfologia, anatomia e fisiologia das partes moles, os caracteres da superfície ventral das carapaças e o mapeamento molecular. 
O exame dos fósseis deve ser criterioso, e cabe analisar as feições comumente preservadas, e de valor sistemático e inovador no sentido filogenético, os denominados proxies. Estes caracteres são: morfologia dorsal, órbitas, forma e ornamentação das margens anterolaterais, convexidade da margem dorsal, região protogástrica, dáctilos e ângulo entre as margens posterior e posterolaterais. Além disso, as características do esterno, apêndices e quelípodes completam o conjunto de características morfoanatômicas para hierarquização filogenética.

Os crustáceos decápodes estão arranjados em quatro grandes grupos, Natantia, Macrocura, Anomura e Brachyura, cujas relações filogenéticas tem sido determinadas ou sugeridas, à medida que novos métodos de análise tenham sido aplicados. Uma das principais causas de divergência de opinião e limitação na definição do seu arranjo sistemático-filogenético é assumir como premissa que os grupos basais são parafiléticos e utilizar para sua definição, caracteres plesiomórficos, favorecendo apenas a separação em grandes grupos-irmãos, como por exemplo, definir que os artrópodes Chelicerata, Myriapoda, Crustacea e Hexapoda são grupos irmãos e tem um ancestral comum. O caminho mais viável é aplicar métodos cladísticos e moleculares, abrigar formas fósseis e recentes, e definir sinapomorfias (Schram 2001).

Os dados sugerem que os decápodes constituem um grupo monofilético, tendência esta extrapolada às suas categorias taxonômicas menores. Desde Glaessner (1969) a sistemática filogenética destes decápodes tem sido aperfeiçoada e vem progressivamente incluindo todos os caracteres, inclusive dos fósseis. Vários arranjos consensuais tem sido propostos, sendo o de Scholtz \& Richter (1995) um dos mais abrangentes.

O táxon considerado o ancestral de todos os decápodes é Palaeopalaemon newberryi, uma lagosta macrocúrea encontrada em rochas do Devoniano Superior da América do Norte. O aparecimento dos eumalacostráceos no registro fóssil é abrupto, por representar um modelo anatômico-fisiológico distinto e inovador, que se diferenciou em um curto intervalo de tempo, a partir das populações periféricas isoladas de trilobitas facopídeos, habitantes dos mares marginais rasos. O estabelecimento deste novo grupo representa um clássico evento de Equilíbrio Pontuado, ocupando as áreas profundas destes mares. Ainda persistem muitas dúvidas sobre o ambiente em que surgiram e qual a trajetória de dispersão dos sincarídeos, peracarídeos, hoplocarídeos e outros malacostráceos, que serão devidamente esclarecidas a partir da descoberta de novos registros paleozóicos, também levando-se em conta os aspectos paleobiogeográficos de todos os táxons intimamente relacionados (Hannibal \& Feldmann 1985; Schram 2001; Schram et al. 1978).

Os anomúreos e braquiúres mais primitivos surgiram entre o Triássico e o Cretáceo, enquanto a grande diversificação e expansão biogeográfica dos braquiúres ocorreu durante o Terciário.

As relações filogenéticas definidas até o momento sugerem que a superfamília Thalassinoidea originou-se provavelmente a partir de um grupo primitivo da infraordem Caridea, pois todos os talassinóideos possuem mero e carpo articulados, bem como exopoditos diferenciados. A família Retroplumidae (gênero Costacopluma) presente na Formação Maria Farinha, é ancestral direta dos ocipodídeos cenozóicos (representados na Formação Pirabas pelo gênero $U c a$ ), ocupando os mesmos nichos ecológicos e com tolerâncias ambientais similares. Também as similaridades morfológicas sugerem parentesco direto e monofiletismo entre Xanthoidea e Portunoidea, e que a partir do Paleoceno, os goneplacídeos, grupo também monofilético com cinco subfamílias, originou outro grupo-irmão, a família Hexapodidae (Schweitzer 2003b). A análise filogenética detalhada entre os membros da família Goneplacidae por Karasawa \& Kato (2003), permitiu aos autores proporem que o gênero Glyphithyreus possui caracteres morfológicos mais afins da subfamília Eucratopsinae, membro do mesmo grande grupo Xanthoidea.

Tudge (1997), em análise de 32 caracteres de 51 táxons de Anomura, visando sua classificação filogenética, reportou que os caracteres sinapomórficos utilizados para o arranjo sistemático do grupo são os relacionados com a origem citoplasmática dos braços microtubulares, e que o parâmetro mais eficaz para investigação das relações filogenéticas corresponde aos detalhes da ultraestrutura espermatozoária. Os resultados apontaram que a infraordem Anomura e suas duas superfamílias, Paguroidea e Galatheoidea não são grupos monofiléticos, pois alguns de seus membros podem estar incluídos no mesmo clado, o que permite caracterizá-los como parafiléticos. A família Diogenidae, também parafilética, é composta por táxons heterogêneos, com afinidades complexas. Em nível de grandes grupos, por meio de evidências moleculares e fósseis, o autor sugeriu que também as infraordens Thalassinidea e Brachyura são parafiléticas, e que Anomura e Thalassinidea são grupos-irmãos, bem como Astacidea e Anomura/Brachyura, e que os palinuros primitivos são intimamente relacionados com os Thalassinidea. Por fim, Tudge (op. cit.) definiu que Anomura e Thalassinidea são também grupos-irmãos, através de similaridades morfológicas tanto nos estágios larvais quanto adultos.

Biogeografia Histórica A Biogeografia dos crustáceos decápodes deve estar baseada nas evidências positivas, pois a ausência de táxons em áreas particulares não significa que os mesmos ali não estiveram presentes.

A teoria da tectônica de placas e o reconhecimento de eventos biogeográficos de vicariância favoreceram o estabelecimento dos padrões de distribuição e rotas de dispersão destes artrópodes, dependentes da geografia regional e fatores oceanográficos, além da preservação do registro e grau de detalhamento da pesquisa nas regiões estudadas.

A distribuição biogeográfica dos decápodes cretáceos e terciários mostra que houve intercâmbio entre os hemisférios norte e sul, através da caracterização de padrões de distribuição anfitropical e bipolar entre o Jurássico e o Eoceno, e que muitos deles tem sido reconhecidos em ambientes rasos e profundos em regiões de baixa latitude. Este intercâmbio foi mais intenso 
durante os momentos de aquecimento da água do mar, principalmente durante o Ótimo Climático do Mioceno Médio (OCMM), que aumentou a zona de influência das águas quentes no Pacífico Norte e águas costeiras do Atlântico Sul na Argentina, favorecendo a introdução de novos grupos tropicais e subtropicais. A modificação dos padrões de correntes oceânicas favoreceu a dispersão larval da Europa e África do Norte para a América do Norte, ao mesmo tempo em que isolou a Antártica, fazendo com que esta região perdesse o papel de significativa área fonte de origem de carcinoelementos (Feldmann \& Schweitzer 2006).

A grande maioria dos táxons que tiveram seu ponto de origem nas américas tropical e subtropical, entre o Cretáceo e o Mioceno, ali permaneceram endêmicos até o Eoceno aproximadamente. A área foi ocupada também por gêneros que surgiram nas regiões do Atlântico Norte, Mar de Tethys, altas latitudes sul e Pacífico Norte, onde nesta última é reconhecido igualmente o padrão de endemismo paralelo (Schweitzer et al. 2002). Também as carcinofaunas cretácicas e terciárias do Chile e Argentina são bem distintas de outras regiões geográficas, devido a barreiras termais e tectônicas (Feldmann et al. 1998).

A carcinofauna do Cretáceo da Argentina é influenciada por elementos atlânticos de águas quentes, e sua proliferação coincide com a subida relativa do nível do mar e início de sedimentação carbonática na Bacia de Neunquén. Este conjunto substitui o préMaastrichtiano, tipicamente antártico de águas frias e altas latitudes (Feldmann et al. 1995).

Apesar da falta de registros significativos, os carcinoelementos indicaram que no intervalo entre o Cretáceo e o Mioceno, houve tanto eventos de origem e diversificação, quanto de extinção, em proporções equilibradas. Também as pesquisas apontaram que o Eoceno foi um tempo de irradiação genérica, enquanto no Cretáceo a diversificação se deu em nível de famílias. Estas irradiações micro e macroevolutivas foram favorecidas pela elevação do nível do mar e clima quente, que criaram uma grande variedade de nichos e habitats onde os decápodes bem se adaptaram (Feldmann et al. 1998).

A queda de asteróides que desencadeou eventos de extinção filética e final em muitos grupos afetou igualmente as carcinofaunas. Estudos na região de Chicxulub no México e comparação com outras áreas permitiram estabelecer que as formas de altas latitudes possuem ocorrência geológica contínua, e que nas águas marinhas de baixas latitudes, muitos táxons desapareceram, pois a queda dos asteróides destruiu as regiões onshore e aumentou a descarga de fluxos de sedimentos nas regiões offshore, desencadeada por tsunamis. Após este evento, houve reocupação por táxons deles derivados oriundos de altas latitudes norte (Vega et al. 2007).

O registro temporal descontínuo dos isópodes (Fig. 2) impede detalhamento sobre sua rota de dispersão (Wieder \& Feldmann 1992). Para melhor entendimento do comportamento biogeográfico dos malacostráceos cenozóicos brasileiros apresenta-se abaixo os dados estão arranjados por superfamílias.
SUPERFAMÍLIA PALEOMONOIDEA O estabelecimento da Biogeografia Histórica deste grupo (Fig. 2) é dificultada pela escassez e descontinuidade do seu registro fóssil. Os primeiros registros datam do Triássico passando por uma irradiação crescente por todo o Mesozóico na Europa, América do Norte e China, e em tempos eocênicos ocupando também a América Central, e no Oligoceno sendo registrados no Brasil (formações Tremembé e Cícero Dantas, representado pelos gêneros Bechleja e Propalaemon). É possível que o grupo tenha como ponto de surgimento o Atlântico leste e dispersado em seguida pelo Atlântico Sul até atingir o Brasil (Feldmann \& Schweitzer 2006).

\section{SUPERFAMÍLIAS CALIANASSOIDEA E PAGUROI-}

$D E A$ No Brasil, estas superfamílias ocorrem nas camadas da Formação Maria Farinha, onde os calianassóideos estão representados pelos gêneros Calianassa, Ctenocheles, Protocalianassa e Upogebia, enquanto os paguróideos pelo gênero Dardanus (Fig. 2). Os registros mais antigos dos calianassóideos são do Cretáceo Inferior a Médio da Austrália e Cretáceo Superior da Europa, Madagascar e África do Sul. No Paleoceno o grupo ocorre na região temperada da Argentina e nordeste brasileiro. Considerando que o ancestral desta superfamília é um carídeo tipicamente da América do Norte e Central, e que o gênero Protocalianassa é considerado tipicamente um elemento tetiano, extrapola-se por analogia que a superfamília Calianassoidea teve como ponto de origem as regiões de baixas latitudes do Atlântico Central e Mar de Tethys (Feldmann \& Schweitzer 2006).

Considerando as relações filogenéticas que estabelecem a natureza de grupos-irmãos, assume-se aqui que a Biogeografia Histórica dos Paguroidea tenha tido o mesmo padrão de origem e dispersão dos Calianassoidea.

SUPERFAMÍLIA CALAPPOIDEA Cada família do grande grupo Calappoidea (Fig. 3) tem uma origem e história de dispersão distintas, embora haja semelhanças em muitos aspectos. Seus aspectos biogeográficos foram sintetizados a partir de Schweitzer \& Feldmann (2000a) e Feldman \& Schweitzer (2006).

A família Neocarcinidae (Aptiano-Oligoceno) pode representar a linhagem ancestral da superfamília. Foi reconhecida em estratos da Europa continental e meio leste, África, Índia, Japão, Antártica, Américas do Norte, Central e Sul, inclusive no Brasil, onde ocorre na Formação Maria Farinha com o gênero Necrocarcinus. Sua ampla distribuição geográfica, em particular no Cretáceo Inferior da Colômbia e Cretáceo Superior da Antártica, sugere sua adaptação a diversos climas, e que sua dispersão se deu do Atlântico Norte para a região do Atlântico central e Tethys, e também para as altas latitudes sul por meio de correntes superficiais.

A família Hepatidae (K-R) também foi amplamente distribuída e de maneira mais intensa a partir do Eoceno até os dias atuais. Seus registros fósseis e recentes abrangem a Europa, África, costas leste e oeste das américas do Norte, Central e Sul, região caribeana, México e Java. Atualmente é típica de mares rasos tropicais e, portanto com uma representatividade menor em rela- 
Família Cirolanidae
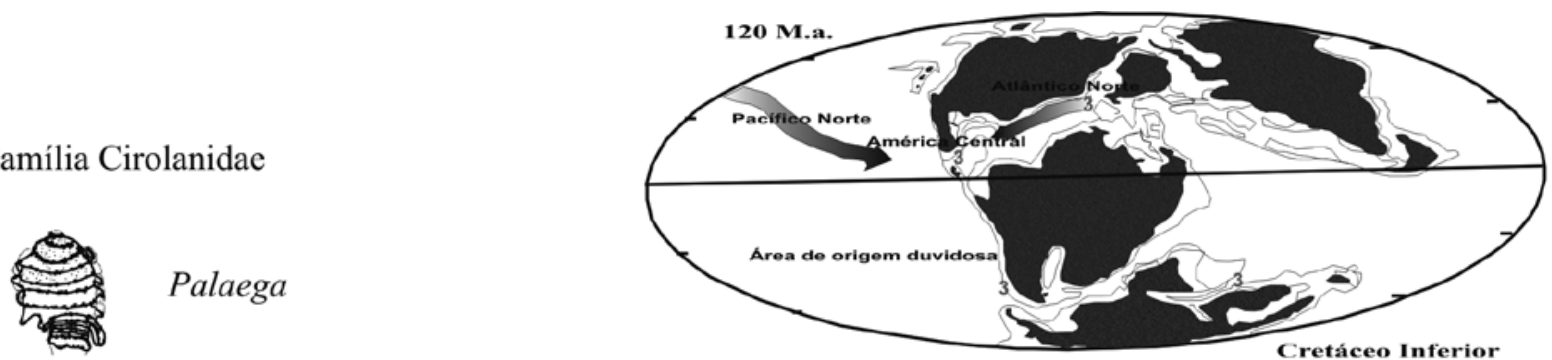

Superfamília Paleomonoidea

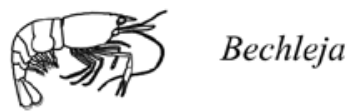

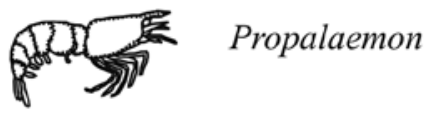

Superfamília Calianassoidea

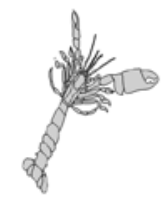

Calianassa

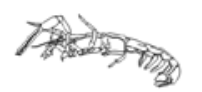

Ctenocheles

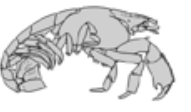

Upogebia
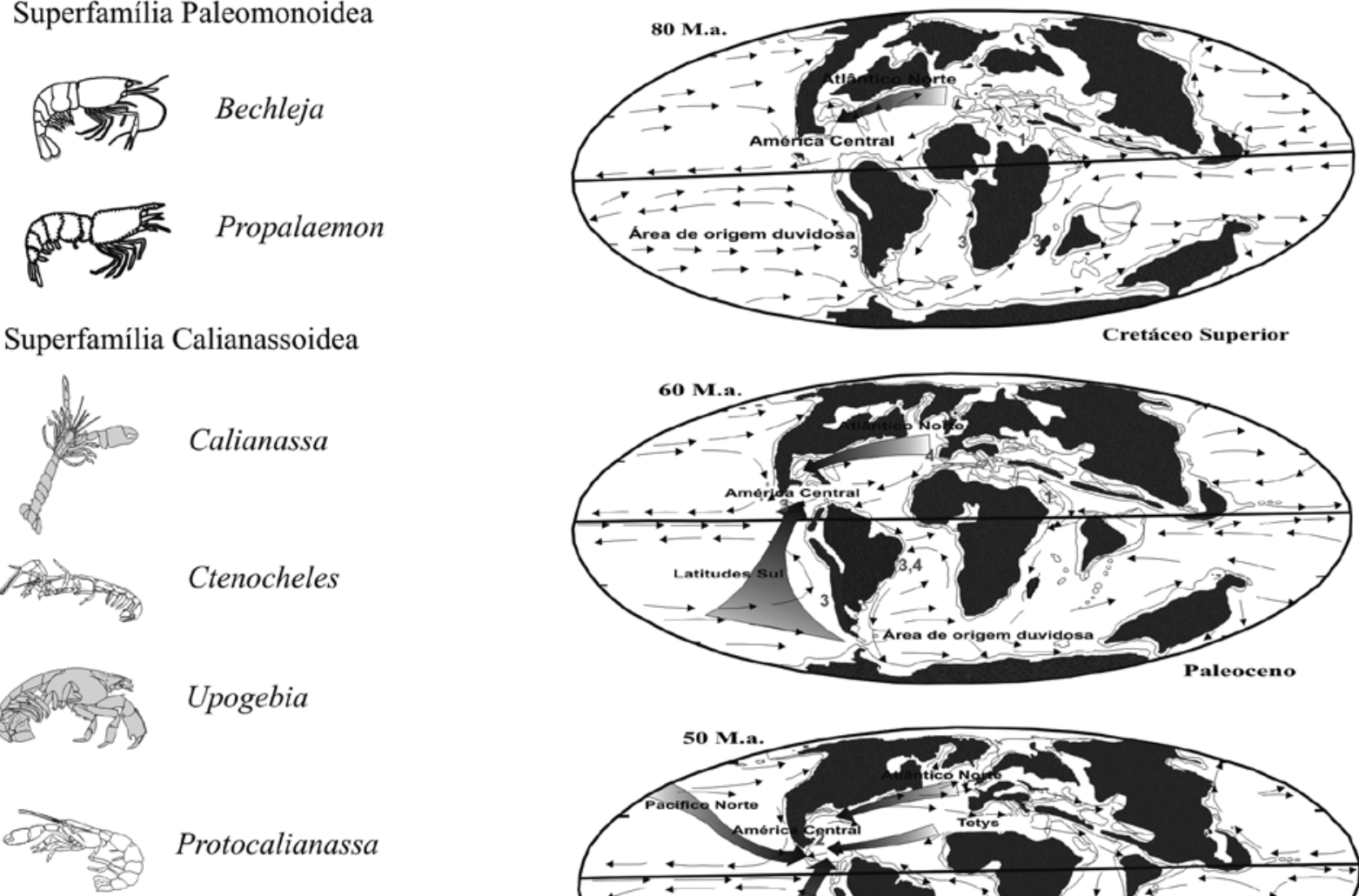

Protocalianassa

Superfamília Paguroidea

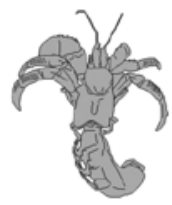

Dardanus
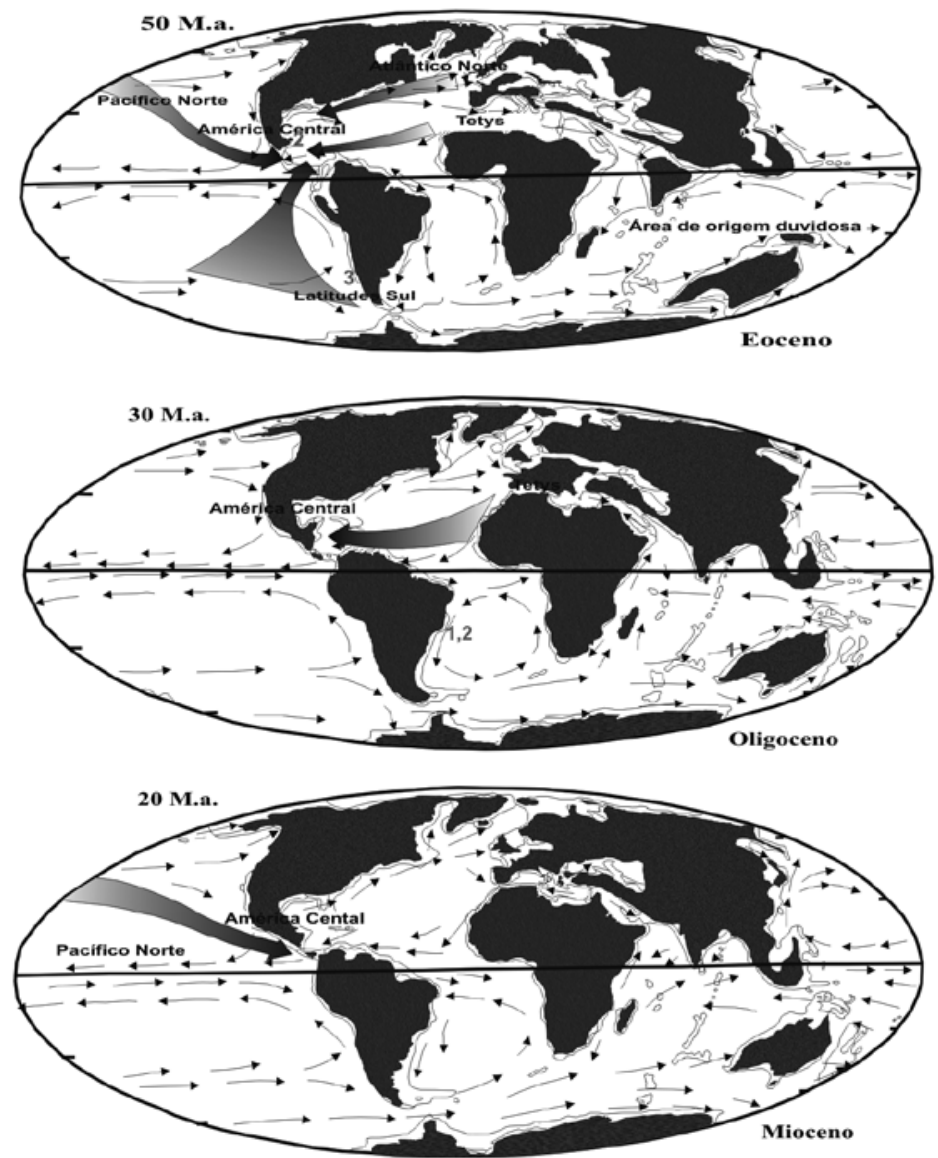

Figura 2 - Distribuição Biogeográfica e Biocronológica da Família (1)Cirolanidae e superfamílias (2)Paleomonoidea, (3)Calianassoidea e (4)Paguroidea e seus respectivos gêneros (baseado em Schweitzer et al. 2002). 
ção às do passado, que foram de clima temperado, mais tolerantes ecologicamente. No Brasil está representada pelo gênero Hepatella (Eoceno-Oligoceno), elemento comum na carcinofauna da Formação Pirabas.

A família Calappidae (Paleoceno-Recente) é típica de baixas latitudes tropicais a temperadas. Os dados levantados sugerem surgimento no Atlântico e Mar de Tethys, de onde dispersou e diversificou por correntes superficiais, cuja adaptação a todos os tipos de substrato e batimetrias favoreceu sua rápida dispersão biogeográfica. No Brasil está representada pelos gêneros Acanthocarpus, Calappa, Calappilia, e Typilobus, nos estratos da Formação Pirabas, cuja distribuição geográfica estende-se à Europa, leste da África, Mediterrâneo, Mar Vermelho, Japão, Austrália, Pacífico central, leste das américas do Norte, Central e Sul, regiões Indo Pacífica e Caribeana, o que sugere seu aparecimento no Mar de Tethys e leste da América do Norte. A distribuição bipolar pode significar simples dispersão ou fragmentação de uma ampla distribuição regional prévia, desencadeada pela formação do Oceano Atlântico Sul e modificações no sistema de correntes marinhas superficiais.

SUPERFAMÍLIA PORTUNOIDEA Os Portunoidea surgiram em regiões de baixas latitudes da região caribeana, incluindo também o México, sul dos Estados Unidos e Brasil, irradiando em seguida para as regiões temperadas do hemisfério sul. Estes primeiros portunóideos compuseram a família Carcineretidae, considerado o seu ramo basal, restrito ao Cretáceo, tendo daí dispersado e irradiado. Entre o Paleoceno e o Mioceno, nova radiação e dispersão ocorreu também na região caribeana, onde se diferenciaram as famílias Geryonidae e Portunidae, que se espalharam por todas as latitudes, sendo hoje um grande grupo cosmopolita. Os registros mais antigos das duas famílias tipicamente cenozóicas, correspondem aos gêneros Portunus, no Oligoceno da Nova Zelândia e Callinectes no Eoceno da Antártica, que no Mioceno já habitavam também a região caribeana. Nos tempos miocênicos também surgiram nas regiões tropicais os gêneros Euphylax, Necronectes e Scylla que dispersaram para Trinidad, Barbados, Venezuela, Equador, Peru e Brasil. A família Portunidae dispersou para o Atlântico Norte e Pacífico através do estreito do Panamá e mar de Tethys. A partir dos portunídeos que ocupavam a Argentina, Nova Zelândia e Antártica, surgiu uma nova família, Geryonidae, por peramorfose (Schweitzer \& Feldmann 2000b, Feldmann \& Schweitzer 2006).

A superfamília Portunoidea é a mais abundante e diversificada de crustáceos decápodes fósseis no Brasil (Fig. 3), representada na Formação Pirabas pelos gêneros Arenaeus, Callinectes, Euphylax, Necronectes, Portunus e Scylla. Considerando o comportamento biogeográfico da família Portunidae durante o Mioceno, sugere-se aqui por analogia que o gênero Arenaeus também tenha surgido na região caribeana.

SUPERFAMÍLIA XANTHOIDEA Segundo Schweitzer (2003 a,b) os dados sobre a história geológica, di- vergência de linhagens, estimativas de idades de seus ancestrais, e a polarização dos seus caracteres, permitiram distinguir os caracteres primitivos e derivados da superfamília Xanthoidea (Fig. 3), e dar suporte para seu arranjo em cladogramas. Os caracteres sinapomórficos dos xantóideos bem estabelecidos já nas duas famílias tipicamente cretácicas, Goneplacidae e Hexapodidae, e em Carpiliidae, Eriphiidae e Pseodoziidae, primeiramente reconhecidas no Eoceno, sugerem que a superfamília expandiu e irradiou continuamente desde quando surgiram. As similaridades morfológicas e funcionais entre as três famílias eocênicas, e mais Zanthopsidae, atestam uma origem comum para todas, a partir de algum táxon intimamente relacionado com os goneplacídeos e hexapodídeos do Cretáceo.

A família Goneplacidae foi comum em latitudes tropicais a temperadas, e surgiu na região do Mar de Tethys. Está representada no Brasil pelo gênero Glyphithyreus na Formação Maria Farinha, também reconhecido no Eoceno dos Estados Unidos, Mioceno da Bacia do Mediterrâneo (correspondente a porção norte do Mar de Tethys) e Hungria, bem como guarda afinidades com os carcinoelementos marinhos atuais da Itália. A sua ampla distribuição biogeográfica sugere que sua dispersão para o Atlântico Norte e América do Sul foi viabilizada e bem sucedida pelas correntes superficiais no sentido leste-oeste, permitindo sua instalação nas linhas de costa das regiões supracitadas (Feldmann et al. 1995, 1998).

As famílias Xanthidae e Grapsidae surgiram na região caribeana durante o Maastrichtiano, registradas no México e Pacífico Norte, além do Eoceno e Oligoceno, também do México, e Mioceno do Brasil (Vega et al. 2001a). Na Formação Pirabas, a família Xanthidae está representada pelos gêneros Tetraxanthus e Panopeus, que surgiram respectivamente na região caribeana e Pacífico Norte, ocupando em seguida também as regiões temperadas. Martins-Neto (2001) propôs um novo gênero, Paratumidocarcinus, cuja distribuição geográfica limitada à Formação Pirabas, impede tecer considerações sobre sua Biogeografia Histórica. Também no Mioceno marinho do norte brasileiro, ocorre o representante da família Grapsidae, Sesarma, gênero cosmopolita atualmente em áreas de baixas latitudes, e que parece ter surgido também na região caribeana, dispersando gradual e crescentemente desde o Oligoceno, quando surgiu.

SUPERFAMÍLIAS PARTHENOPOIDEA E CANCROI$D E A$ A Biogeografia Histórica destas duas superfamílias (Fig. 3) que no Brasil estão registradas na Formação Pirabas com um gênero cada, Parthenope e Tasadia, foi similar e simultâneo com a Superfamília Portunoidea. Os registros de Parthenope no Paleoceno do leste da América do Norte e no Mioceno de Trinidad, Barbados, Venezuela, Equador, Peru e Brasil, sugere que este surgiu na região da América Central (Feldmann \& Schweitzer, 2006). O gênero Tasadia surgiu no Mioceno, e assim como a maioria dos cancrídeos deve ter surgido no Oceano Pacífico Norte, tendo em seguida dispersado para o Oceano Atlântico 
Superfamília Calappoidea

Acanthocarpus
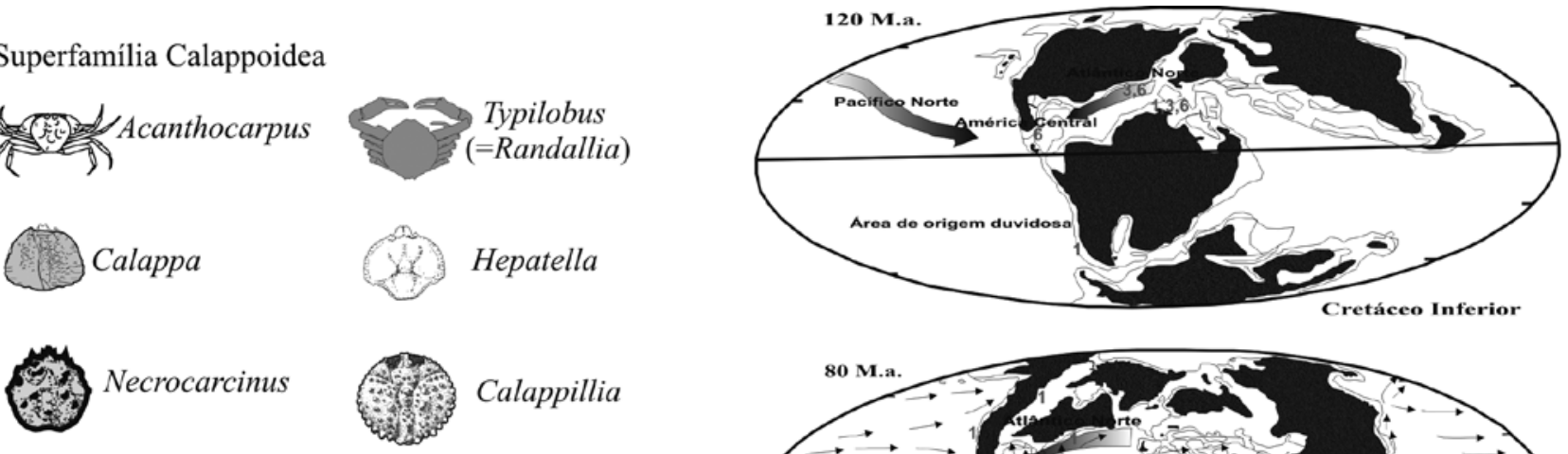

Hepatella

Calappillia

Superfamília Portunoidea
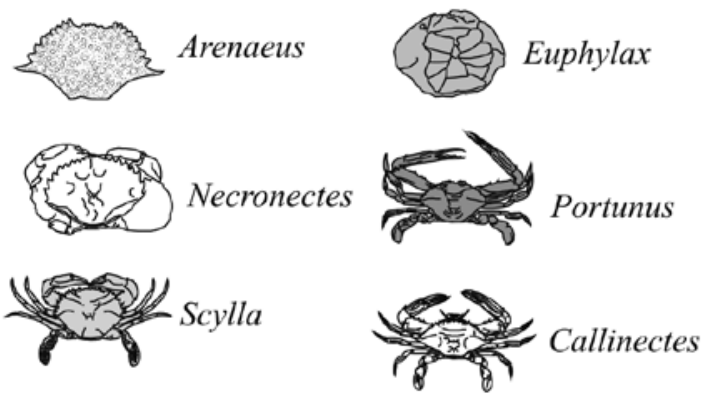

Superfamília Xanthoidea
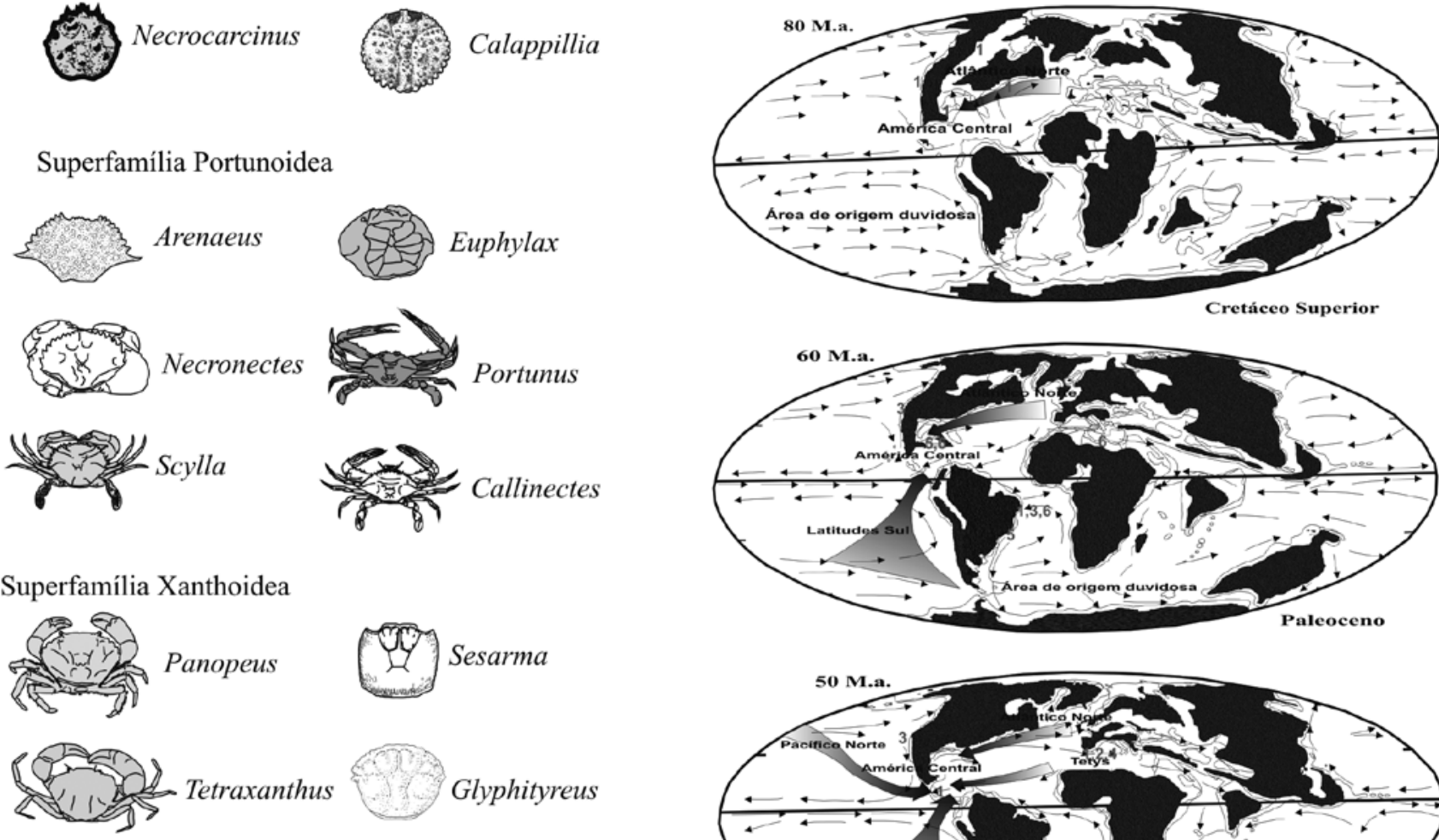

Superfamília Parthenopoidea

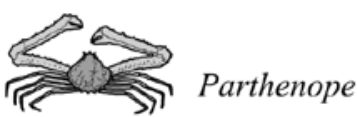

Glyphityreus

Superfamília Cancroidea

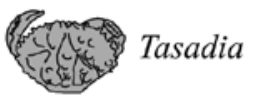

Superfamília Ocypodoidea
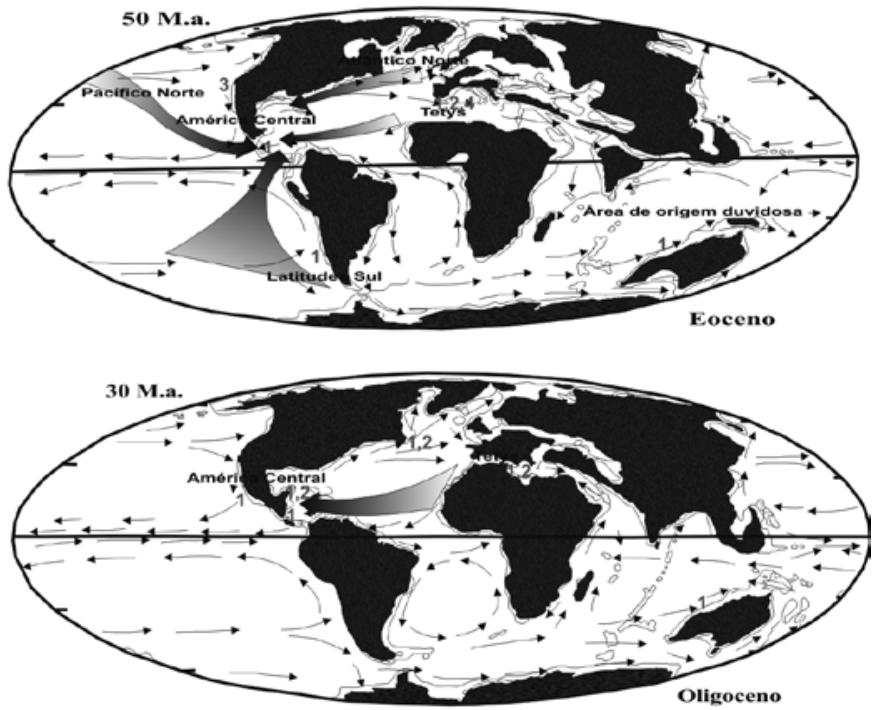

(1) Costacopluma $\begin{aligned} & U c a \\ & (=\text { Paratumidocarcinus })\end{aligned}$

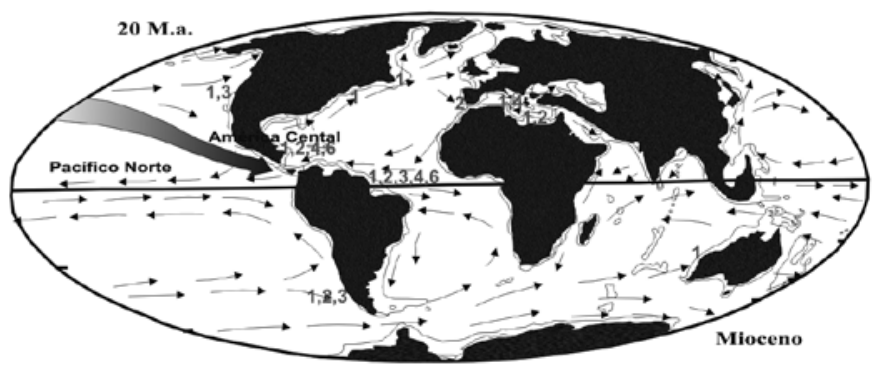

Figura 3 - Distribuição Biogeográfica e Biocronológica das superfamílias (1)Callapoidea, (2)Portunoidea, (3)Xanthoidea, (4)Parthenopoidea, (5)Cancroidea e (6)Ocypodoidea e seus respectivos gêneros (baseado em Schweitzer et al. 2002). 
Norte, Central e Sul (Schweitzer \& Feldmann 2000c).

SUPERFAMÍLIA OCYPODOIDEA No Cenozóico brasileiro esta superfamília tem dois registros, em tempos geológicos e localidades geográficas distintas, que representam também um grupo monofilético (Fig. 3). No Estado de Pernambuco, a Formação Maria Farinha guarda um rico registro do gênero Costacopluma (família Retroplumidae), que foi abundante entre o Campaniano e o Maastrichtiano e surgiu na América Central e Mar de Tethys, como derivado de Archaeopus, gênero que surgiu na América do Norte (Vega \& Feldmann, 1992). De seu ponto de surgimento, Costacopluma migrou para oeste, sul e sudeste, e assim atingiu a Nigéria, norte da Índia, América Central e Venezuela no Cretáceo Superior, e a Argentina e Brasil no Paleoceno. Constitui-se em um elemento tipicamente tetiano, freqüente em baixas latitudes do hemisfério norte e no Brasil, tendo também atingido a Groenlândia (Feldmann \& Schweitzer 2006; Feldmann et al. 1995; Vega et al. 2007).

E a partir dos retroplumídeos, surgiu na América Central durante o Neógeno, o gênero $U c a$, hoje vivente entre os Estados da Flórida nos Estados Unidos, e Rio Grande do Sul no Brasil (Melo 1996), e como fóssil tem sido registrado unicamente nos estratos da Formação Pirabas. Provavelmente o ponto de origem do gênero $U c a$ foi a região norte da Austrália, em algum momento no início do Cretáceo, e dispersou até chegar na América do Sul.

CONTEXTUALIZAÇÃO A distribuição paleobiogeográfica dos decápodes cenozóicos do Brasil permite enquadrar o seu surgimento, dispersão e irradiação em três dos cinco padrões propostos por Schweitzer (2001) para as carcinofaunas do Oceano Pacífico Norte, a saber: fauna de origem tetiana, fauna de origem de alta latitude sul e fauna anfitropical.

A maior parte da carcinofauna brasileira tem afinidade com a fauna de origem tetiana, que teve basicamente dois caminhos de dispersão, atribuídos a modificações climáticas e paleoceanográficas entre o Cretáceo e o Mioceno. O primeiro, quando os elementos migraram do sentido oeste a partir do sul da Europa e Mar de Tethys, para leste atingindo a costa leste dos Estados Unidos e região caribeana, e em seguida, chegando na costa oeste dos Estados Unidos e América do Sul, pelo corredor americano central. Um segundo caminho parece ter sido a movimentação dos táxons para o leste da Europa e Mar de Tethys e Japão, a partir da costa leste dos Estados Unidos, em um caminho inverso ao primeiro (Schweitzer 2001).

Da fauna de alta latitude sul surgiram táxons que dispersaram para as baixas latitudes do hemisfério norte e posteriormente também áreas do hemisfério sul. Os elementos que permaneceram endêmicos nesta região, pertencentes ás superfamílias Calappoidea, Portunoidea e Xanthoidea, principalmente na Antártica durante o Cretáceo e o Terciário, influenciaram grandemente as carcinofaunas neogênicas da região circunpacífica (Schweitzer 2001).

Finalmente, as faunas anfitropicais cretácicas e que influenciaram na dispersão de seus aparentados cenozóicos, devem ter tido este comportamento biogeográfico a partir da quebra do Pangea, que abriu o Atlântico Sul, modificando os padrões de circulação oceânica, desencadeando fragmentação de populações em componentes norte e sul, resultando em vicariâncias que culminaram com a individualização de dois grandes conjuntos de crustáceos decápodes. Os dados sugerem que os elementos anfitropicais derivados forçam o deslocamento das formas primitivas para as latitudes médias a altas. Os crustáceos decápodes de origem anfitropical no Cenozóico brasileiro são os membros das famílias Portunidae e Cancridae, cujos táxons derivados e mais avançados viveram e muitos ainda vivem nas latitudes baixas de clima tropical, e seus ancestrais distribuem-se nas regiões temperadas (Schweitzer 2001).

CONCLUSÕES O estudo biogeográfico e filogenético da paleocarcinofauna do Cenozóico brasileiro permitiu as seguintes conclusões:

1. Os malacostráceos cenozóicos brasileiros compõem uma das faunas mais representativas da América do Sul para o intervalo temporal compreendido entre o Paleoceno e o Mioceno, estando representadas por nove espécies na Formação Maria Farinha, três na Formação Tremembé e 24 na Formação Pirabas, todos com afinidades tetianas e aspecto moderno;

2. As relações filogenéticas definidas até o momento sugerem que a superfamília Thalassinoidea originou-se provavelmente a partir de um grupo primitivo da infraordem Caridea, pois todos os talassinóideos possuem mero e carpo articulados, bem como exopoditos diferenciados. A família Retroplumidae (gênero Costacopluma), presente na Formação Maria Farinha, é ancestral direta dos ocipodídeos cenozóicos (representados na Formação Pirabas pelo gênero $U c a$ ), ocupando os mesmos nichos ecológicos e com tolerâncias ambientais similares. Também as similaridades morfológicas sugerem parentesco direto e monofiletismo entre Xanthoidea e Portunoidea, e que a partir do Paleoceno, os goneplacídeos, grupo também monofilético com cinco subfamílias, originou outro grupo-irmão, a família Hexapodidae (Schweitzer 2003b). A análise filogenética detalhada entre os membros da família Goneplacidae por Karasawa \& Kato (2003) permitiu aos autores proporem que o gênero Glyphithyreus possui caracteres morfológicos mais afins da subfamília Eucratopsinae, membro do mesmo grande grupo Xanthoidea.

3. A distribuição paleobiogeográfica dos decápodes cenozóicos do Brasil permite enquadrar o seu surgimento, dispersão e irradiação em três dos cinco padrões propostos por Schweitzer (2001), para as carcinofaunas do Oceano Pacífico Norte, a saber fauna de origem tetiana, fauna de origem de alta latitude sul e fauna anfitropical;

4. A maior parte da carcinofauna brasileira tem afinidade com a fauna de origem tetiana, que teve basicamente dois caminhos de dispersão. O primeiro, quando os elementos migraram do sentido oeste a partir do sul da Europa e Mar de Tethys, para leste 
atingindo a costa leste dos Estados Unidos e região caribeana, e em seguida, chegando na costa oeste dos Estados Unidos e América do Sul, pelo corredor americano central. Um segundo caminho, parece ter sido a movimentação dos táxons para o leste da Europa e Mar de Tethys e Japão, a partir da costa leste dos Estados Unidos, em um caminho inverso ao primeiro (Schweitzer 2001). Da fauna de alta latitude sul sur- giram táxons que dispersaram para as baixas latitudes do hemisfério norte e posteriormente também áreas do hemisfério sul. Os elementos que permaneceram endêmicos nesta região, principalmente na Antártica durante o Cretáceo e o Terciário, influenciaram grandemente as carcinofaunas neogênicas da região circun-pacífica (Schweitzer 2001).

\section{Referências}

Almeida, F. F. M., 1958. Vale do Paraíba. In: Relatório Anual do Diretor. Rio de Janeiro, DNPM/DGM, 139:90-91.

Almeida V.A.K. 2003. Espécies de cirolanídeos (IsopodaCrustacea) coletadas na plataforma continental e bancos oceânicos do norte e nordeste do Brasil. Dissertação de Mestrado, Programa de Pós Graduação em Oceanografia, Universidade Federal de Pernambuco, Recife, 118 p.

Beurlen K. 1959. Observações sobre a Formação Maria Farinha, Estado de Pernambuco. Arquivos de Geologia, Escola de Geologia, Universidade de Recife, 1:1-15.

Beurlen K. 1967. Paleontologia da faixa costeira Recife-João Pessoa. Boletim da Soc. Bras. de Geologia, 16(1):73-79.

Cecca F. 2002. Paleobiogeography of marine fossil invertebrates- concepts and methods. London, Taylor \& Francis, $273 \mathrm{p}$.

Feldmann, R.M. 2003. The Decapoda: new initiatives and novel appoaches. Journal of Paleontology, 77(6): 1021-1039.

Feldmann, R.M. 2006. Paleobiogeography of southern hemisfere decapod crustacea. Jl. of Paleontology, 80(1): 83-103.

Feldmann R.M. \& Goolaerts S.2005. Palaega rugosa, a new species of fossil isopod (Crustacea), from Maastrichtian Rocks of Tunisia. Journal of Paleontology, 79(5):10311035.

Feldmann R.M. \& Martins-Neto R.G.1995. Costacopluma nordestina n.sp. (Decapoda: Retroplumidae) from the Maria Farinha Formation (Paleocene) of Brazil. Journal of Paleontology, 69(3):610-611.

Feldmann R.M. \& Schweitzer C.E.2006. Paleobiogeography of Southern Hemisfere Decapod Crustacea. Journal of $\mathrm{Pa}$ leontology, 80(1):83-103.

Feldmann R.M., Casadío S., Chirino-Galvéz L., Aguirre-Urreta M. 1995. Fossil Decapod Crustaceans from the Jaguel and Roca Formations (Maastrichtian-Danian) of the Neunquén Basin, Argentina. Journal of Paleontology, 69(5), The Paleontological Society Memoir 43, 22p.

Feldmann R.M., Bice K.L., Hopkins, C.S., Salva E.W., Pickford K. 1998. Decapod Crustaceans from Eocene Castle Hayne Limestone, North Carolina: Paleoceanographic Implications. Journal of Paleontology, 72(1), The Paleontological Society, Memoir 48, 28p.

Ferreira C.S. 1982. Notas Estratigráficas Sobre o Cenozóico Marinho do Estado do Pará. In: SBG, Simp. Geol. Amazônia, 1, Anais, 1:84-88.

Ferreira C.S. \& Cunha O.R. 1957. Contribuição à Paleontologia do Estado do Pará. Notas sobre a Formação Pirabas com a descrição de novos invertebrados fósseis. 1. (Mollusca- Gastropoda). Boletim do Museu Paraense Emílio Goeldi, nova série Geologia, 2:1-61.

Garassino A., Yanbin S., Schram F.R., Taylor R.S. 2002. Yongji- caris zhejiangensis n.gen.n.sp. (Crustácea, Decapoda, Caridea) from the Lower Cretaceous of Zhejianj Province, China. Bulletin of the Mizunami Fossil Museum, 29:73-80.

Glaessner M.F.1969. Decapoda. In: Moore R.C. (ed.) Treatise on Invertebratre Paleontology. Part R, Arthropoda 4, University of Kansas Press and Geological Society of America, Kansas, v. 2, p. R400-R651.

Góes A.M., Rossetti D.F., Nogueira A.C.R., Toledo P.M. 1990. Modelo deposicional preliminar da Formação Pirabas no nordeste do Pará. Boletim do Museu Paraense Emílio Goeldi, série Ciências da Terra, 2:3-15.

Hannibal J. \& Feldmann R.M. 1985. Newberry's lobster: the earliest decapod. Explorer, 27(1):10-12.

Karasawa H. \& Kato H.2003. The family Goneplacidae MacLeay, 1838 (Crustacea: Decapoda: Brachyura): systematics, phylogeny, and fossil records. Paleontological Research, 7(2):129-151.

Martin J.W. \& Davis G.E.2001. An updated classification of the Recent Crustacea. Natural History Museum of Los Angeles County Science Series, 39:1-124.

Martins-Neto R.G. 2001. Review of Some Crustacea (Isopoda and Decapoda) from Brazilian deposits (Paleozoic, Mesozoic and Cenozoic) with Descriptions of New Taxa. Acta Geológica Leopoldensia, XXIV(52/53):237-254.

Maury C.J. 1925. Fósseis terciários do Brasil com descrição de novas Formas Cretáceas. Rio de Janeiro, Serviço Geológica e Mineralógico do Brasil, Monografia 4, 665 p.

Maury C.J. 1930. O Cretáceo da Parahyba do Norte. Rio de Janeiro, Serviço Geológico e Mineralógico do Brasil, Monografia $8,350 \mathrm{p}$.

Melo G.A.S.1996. Manual de Identificação dos Brachyura (caranguejos e siris) do litoral brasileiro. São Paulo, Editora Plêiade, 604 p.

Morrone J.J. \& Crisci J.V. 1995. Historical Biogeography: introduction to methods. Annual Review of Ecology and Systematics, 26:373-401.

Riccomini C. 1989. O Rift Continental do Sudeste do Brasil. São Paulo, Tese de Doutoramento, Instituto de Geociências, Universidade de São Paulo, 256 p.

Riccomini C., Coimbra A.M., Sant'anna L.G., Brandt Neto M., Valarelli J.V. 1996. Argilominerais do paleolago Tremembé e sistemas deposicionais relacionados (Paleógeno, Rift Continental do Sudeste do Brasil). Revista Brasileira de Geociências, 26:167-180.

Rossetti D.F. 2000. Influence of low amplitude/high frequency relative sea-levels changes in a wave-dominated estuary (Miocene), São Luis Basin, northern Brazil. Sedimentary Geology, 133:295-324.

Rossetti D.F. \& Góes A.M. 2004. Geologia. In: Rossetti D.F. \& 
Góes A.M. (eds.) O Neógeno da Amazônia Oriental. Editora do Museu Paraense Emílio Goeldi, Coleção Friederich Katzer, Belém, p.13-52.

Ruppert E.E., Fox R.S., Barnes R.D. 2005. Crustacea. In: Zoologia dos Invertebrados: uma abordagem funcional evolutiva. Editora Roca, p.702-780.

Scholtz G. \& Richter S.1995. Phylogenetic systematics of the reptantian Decapoda (Crustacea, Malacostraca). Zoological Journal of the Linnean Society, 113:289-328.

Schram F.R.2001. Phylogeny of decapods: moving towards a consensus. Hydrobiologia, 449:1-20.

Schram F.R., Feldmann R.M., Copeland M.J. 1978. The Late Devonian Palaeopalaemonidae Brooks, 1962, and the earliest decapod crustaceans. Journal of Paleontology, 52(6):1375-1387.

Schweitzer C.E.2001. Paleobiogeography of Cretaceous and Tertiary Decapod Crustaceans of the North Pacific Ocean. Journal of Paleontology, 75(4):808-826.

Schweitzer C.E.2003a. Utility of proxy Characters for Classification of Fossils: an example from the Fossil Xanthoidea (Crustacea: Decapoda: Brachyura). Journal of Paleontology, 77(6):1107-1128.

Schweitzer C.E. 2003b. Progress on the fossil Xanhoidea MacLeay, 1838 (Decapoda: Brachyura). Contributions to Zoology, 72(2/3):181-186.

Schweitzer C.E. \& Feldmann R.M. 2000a. New species of Calappid Crabs from Western North America and Reconsideration of the Calappidae sensu lato. Journal of Paleontology, 74(2):230-246.

Schweitzer C.E. \& Feldmann R.M. 2000b.New fossil portunids from Washington, USA and Argentina, and a re-volution of generic and family relationships within the Portunoidea Rafinesque, 1815 (Decapoda: Brachyura).Journal of Paleontology, 74(4):636-653.

Schweitzer C.E. \& Feldmann R.M. 2000c. Re-evaluation of the Cancridae Latreille, 1802 (Decapoda: Brachyura) including three new genera and three new species. Contributions to Zoology, 69(4):223-250.

Schweitzer C.E., Feldmann R.M., Gonzáles-Barba G., Vega F.J. 2002. New Crabs from the Eocene and Oligocene of Baja Califórnia Sur, México and an assessment of the evolutionary and paleobiogeographic implications of Mexican fossil, decapods. Journal of Paleontology, 76(6), Memoir 59, The Paleontological Society, $43 \mathrm{p}$.

Storer T.I. 2003. Classe Crustacea: Crustáceos. In: __ _ Zoologia Geral, Cia Editora Nacional, São Paulo, p.484-503.

Suguio K. 1969. Contribuição à Geologia da Bacia de Taubaté, Vale do Paraíba-Estado de São Paulo. São Paulo, Tese de Doutoramento, Inst. de Geociências, USP, 106 p.

Távora V. A.2001. Sobre a validade de Uca maracoani antiqua Brito, 1972 na Formação Pirabas - Estado do Pará. Revista Brasileira de Paleontologia, 2:100.

Távora V.A. \& Miranda M.C.C. 2004. Sistemática e Tafonomia de uma fáunula de crustáceos decápodes da Formação Maria Farinha (Paleoceno), Estado de Pernambuco, Brasil. Revista Brasileira de Paleontologia, 7(1):45-52.

Távora V.A. \& Souza S.R. 2000. Primeiro registro fóssil de Portunus spinimanus e Tetraxanthus rathbunae no Brasil- Formação Pirabas no Estado do Pará. In: Soc. Bras. de Carcinologia, Congresso Brasileiro sobre Crustáceos, 1,
São Pedro, Programa e Resumos do I Congresso Brasileiro sobre Crustáceos, p. 191.

Távora V.A. \& Silva Junior O. G. 2002. Petrografia e Geoquímica dos carcinólitos da ecofácies Baunilha Grande da Formação Pirabas (Eomioceno) - Estado do Pará. Revista Brasileira de Paleontologia, 3:5-16.

Távora V.A. \& Viana M.S. S.2003. Carcinolites of the Pirabas Formation (Early Miocene), Pará State, Brazil. Boletim do Museu Nacional. Nova Série Geologia, 71:1-11.

Távora V.A., Miranda V.F. O., Pinto M.L. 2005a. Estudo Sistemático dos Calianassídeos (Crustacea- Decapoda) da Formação Maria Farinha (Paleoceno), Estado de Pernambuco. Revista Brasileira de Geociências, 35(3):401-406.

Távora V.A., Miranda V.F.O., Viegas L.G.F., Galvão P.H.F. 2005b. Novos Registros de Crustáceos Decápodes do Cenozóico (Paleoceno e Mioceno Inferior) do Brasil. Revista Brasileira de Geociências, 35(3):393-400.

Távora V.A., Silva F.A., Souza E.J. 2006. Fossildiagênese e Geoquímica dos crustáceos decápodes da Formação Maria Farinha (Paleoceno), Estado de Pernambuco, Brasil. Revista Brasileira de Geociências, 36(1):81-90.

Távora V.A., Mesquita N., Souza S.R., Cacela A.S.M., Teixeira S.G. 2002. Sistemática e Tafonomia dos crustáceos decápodes da ecofácies Capanema da Formação Pirabas (Mioceno Inferior), Estado do Pará. Revista Brasileira de Geociências, 32(2):223-230.

Torres-Ribeiro M. 2004. Fácies microclásticas de um sistema lacustre oligocênico do sudeste do Brasil (Formação Tremembé, bacia de Taubaté). Rio de Janeiro, Dissertação de Mestrado, Instituto de Geociências, Universidade Federal do Rio de Janeiro, 122 p.

Tudge C.C. 1997. Phylogeny of the Anomura (Decapoda: Crustacea): Spermatozoa and Spermatophore Morfological Evidence. Contributions to Zoology, 67(2):125-141.

Vega F.J. \& Feldmann R.M. 1992. Occurrence of Costacopluma (Decapoda: Brachyura: Retroplumidae) in the Maastrichtian of southern Mexico and its paleobiogeographic implications. Annalles of Carnegie Museum, 61:133-152.

Vega F.J., Feldmann R.M., Garcia-Barrera P., Filkorn H., Pimentel F., Avendaño J. 2001a. Maastrichtian Crustacea (Brachyura: Decapoda) from the Ocozocuautla Formation in Chiapas, Southeast Mexico. Journal of Paleontology, 75(2):319-329.

Vega F.J., Cosma T., Coutiño M.A., Feldmann R.M., Nyborg T.G., Schweitzer C.E., Waugh D.A. 2001b. New middle Eocene Decapods (Crustacea) from Chiapas, Mexico. Journal of Paleontlogy, 75(5):929-946.

Vega F.J., Nyborg T., Fraaye H.B., Espinosa B. 2007. Paleocene Decapod Crustacea from the Rancho Nuevo Formation (Parras Basin-Difunta Group), Northeastern México.Journal of Paleontology, 81(6):1432-1441.

White C. 1887. Contribuições à Paleontologia do Brasil. Arquivos do Museu Nacional, 7:1-273.

Wieder R.W. \& Feldmann R.M. 1992. Mesozoic and Cenozoic Fossil Isopods of North America. Journal of Paleontology, 66(6):958-972.

Manuscrito ID 13313 Submetido em 20 de janeiro de 2009 Aceito em 17 de fevereiro de 2010 